\title{
POR UMA HISTÓRIA DA ARTE DE \\ "OBJETOS INCOMPLETOS" - \\ ENTREVISTA COM SÔNIA SALZSTEIN
}

ANA CÂNDIDA DE AVELAR

\section{RESUMO}

$\mathrm{Na}$ entrevista a seguir, a professora de Artes Visuais Sônia Salzstein discute a história da arte que se produz no Brasil, o formalismo e a História Social da Arte dentro desse debate e as mudanças no cenário das instituições artísticas brasileiras, a partir de sua própria experiência como docente e crítica. Este depoimento integra o projeto "História e crítica de arte hoje: referências, diálogos", desenvolvido pelo Núcleo de Pesquisa e Mediação do Centro Universitário Maria Antonia, da USP, sob a coordenação de Ana Cândida de Avelar.

Palavras-chave: Sônia Salzstein; História da Arte no Brasil; História Social da Arte; formalismo.

\section{ABSTRACT}

In the following interview, Professor of Visual Arts Sônia Salzstein discusses the History of Art produced in Brazil, formalism and Social History of Art in this debate and changes in the scenario of Brazilian art institutions, from the perspective of her own experience as a lecturer and critic. This statement is part of the project "History and art criticism today: references, dialogues", developed by the Núcleo de Pesquisa e Mediação do Centro Universitário Maria Antonia, da USP, coordinated by Ana Cândida Avelar.

KEYWORDS: Sônia Salzstein; History of Art in Brazil; Social History of Art; formalism.

O projeto de pesquisa de longa duração "História e crítica de arte hoje: referências, diálogos", visa mapear, por meio de entrevistas, as perspectivas teóricas de alguns dos principais historiadores e críticos de arte em atividade atualmente no país. A entrevista realizada com Sônia Salzstein, professora do Departamento de Artes Plásticas da Universidade de São Paulo, inaugurou o projeto, cuja ideia central é constituir um quadro de referências que orientam o pensamento sobre arte no Brasil, contribuindo para o trabalho dos estudiosos de Teoria, Crítica e História da Arte ao revelar modelos teóricos e pontos de vista que constituem a epistemologia da área entre nós. Do ponto de vista 
desse projeto, a História da Arte e a atividade crítica são indissociáveis na tradição brasileira e, sendo assim, as entrevistas devem contemplar também convidados externos ao meio acadêmico.

O projeto foi proposto por mim, em 2013 , como uma das atividades do Núcleo de Pesquisa e Mediação do Centro Universitário Maria Antonia, da USP, do qual sou coordenadora, e realizado com a participação dos estagiários ${ }^{1}$.

Atualmente, novos estagiários do Núcleo integram as atividades, que, assim, contribuem para a formação desses alunos, tanto por meio do aprofundamento no estudo da história e da crítica de arte no cenário brasileiro e internacional, como por meio do contato direto com os entrevistados, que, ao enviarem previamente suas referências teóricas, auxiliam na devida preparação do grupo para a conversa.

Diante do quadro atual de ampliação e especialização do trabalho de críticos, curadores e historiadores da arte, com a abertura de cursos de graduação, centros culturais, públicos e privados, e políticas públicas de incentivo a projetos de publicações e exposições, faz-se necessário um adensamento teórico da formação desses profissionais. Nesse sentido, pensar sobre como se faz História da Arte no país hoje também oferece instrumentos para a autorreflexão e o aprimoramento daqueles que se inscrevem nesse campo de atuação diversificado.

Considerando que a História Social da Arte e o formalismo são referências centrais no pensamento sobre arte no Brasil pelo menos desde os anos 1960, pedimos a Sônia Salzstein que discutisse essas abordagens a partir de sua própria experiência. O resultado é um depoimento lúcido e uma avaliação extensa do ambiente artístico, principalmente em São Paulo, apontando o papel atual da universidade no debate sobre arte, os encaminhamentos da crítica de arte contemporânea e as transformações e necessidades das instituições públicas dedicadas às artes visuais, bem como dos desafios colocados para a atuação dos novos profissionais nos espaços culturais.

\section{Núcleo de Pesquisa e Mediação do Centro Universitário Maria} Antonia - Como foi sua formação como historiadora e crítica de arte?

Embora tenha passado por todas as etapas da vida universitária, julgo minha formação essencialmente autodidata. Fui montando lacunas, conforme percebia que elas apareciam. Essa pergunta pressuporia alguém com uma formação mais rigorosa no campo disciplinar do que aquela que tenho. Fiz uma graduação em uma escola de artes plásticas, tive interesse por trabalho gráfico e, quando jovem, cheguei a fazer algumas coisas que hoje não me interessam, mas evidentemente como diletante. Mais tarde, percebendo que tinha saído da universidade com uma formação inconsistente, fui para a Filosofia, estudei mais rigorosamente, mas não cheguei a concluir a graduação, embora tenha

\begin{abstract}
[1] Da preparação e execução desta entrevista participaram os estagiários Ana Carolina Roman, Caio Guedes, Leandro dos Santos, Mariana Cobuci e Irana Magalhães, além de Thiara Grizilli. Agradeço a João Bandeira, coordenador de Artes Visuais do Centro Universitário Maria Antonia, pelo apoio às atividades do Núcleo e, em especial, ao projeto.
\end{abstract}


feito quatro anos muito produtivos nos estudos, em termos de escrever, do contato com os professores. Acabei fazendo a pós-graduação na Filosofia. No Brasil, ela dá um eixo, cria um quadro de referências importantes, interlocutores. Embora a minha área de formação seja primordialmente voltada à questão contemporânea, cada vez mais me senti impelida a ter uma cultura histórica mais sedimentada para descontar a falta de tradição das universidades brasileiras de um campo disciplinar na área de arte. Então, titubeei muito, fui para diversas áreas e até hoje estou tentando melhorar uma formação lacunar.

Entendemos que a História Social da Arte e o formalismo - termo atualmente controverso - são abordagens centrais até hoje para a História da Arte que se faz no Brasil. Você poderia falar um pouco sobre essas abordagens a partir da sua experiência?

Um ensaio dos anos 1970 do T.J. Clark [a entrevistada provavelmente se refere ao artigo "As condições da criação artística", de 1974] é um texto importante, de formação, para tratar desse assunto inclusive em sala de aula. É um texto de quando ele era razoavelmente jovem, então não sei se ele se diria um historiador social da arte. Quando o convidamos, através de uma iniciativa conjunta do Departamento de Artes Plásticas, da Escola de Comunicações e Artes da Universidade de São Paulo, e do Centro Universitário Maria Antonia, houve até uma situação curiosa. Perguntei a ele como queria ser identificado nos créditos do material de divulgação. "Historiador social" parecia-me algo que confina mais do que aponta para uma intervenção contundente. Assim, chegamos à conclusão de que seria "historiador com foco em História Social”, embora seja claro que a tradição marxista, portanto, a tradição de uma História Social da Arte, tem importância na constituição do trabalho e na própria trajetória intelectual do Clark. Não sei se ele usaria os mesmos termos hoje.

Antes mesmo de ser traduzido aqui no Brasil, ele já era uma referência muito importante para mim. Tomei contato $\operatorname{com} A$ pintura da vida moderna: Paris na arte de Manet e seus seguidores (São Paulo: Companhia das Letras, 2004) na versão original, logo quando comecei a dar aulas como professora convidada no Departamento de Artes Plásticas da USP, antes de me submeter ao concurso.

Esse livro foi uma descoberta para mim no fim de 1990 e continua sendo uma referência na abordagem do impressionismo, porque o Clark é um autor com uma visão muito fina da História Social, fazendo frequentes análises de obras e sem usar a palavra "contexto". Essa palavra é sempre perturbadora em autores ligados à tradição marxista porque sugere que a obra é uma coisa que está fora do contexto. $\mathrm{O}$ Clark tem essa posição queébastante exigentee rara de seencontrar na tradição marxista menos sofisticada. No campo da arte, essa diferença 
entre abordagens é importante: a tradição da Escola de Frankfurté admirável, mas há uma vulgata marxista que é determinista e positivista quando se debruça sobre arte moderna e contemporânea. O Clark me surpreendeu porque encontrei nele o argumento social encravado no cerne da obra, pois ele faz a análise formal da obra aliada a uma percepção sofisticada do trabalho de arte. Ele consegue destrinchar certas estruturas do trabalho de arte que são representações formadoras de mentalidades. Essa foi a grande novidade. Apesar de o Clark ser uma referência importante para meu trabalho, fica sempre uma interrogação em relação ao desconforto dele em lidar com arte contemporânea, embora ele transmita muito bem para a política os temas mais contundentes na situação atual. É curioso que ele não tenha a mesma energia para a arte contemporânea. Então, fico pensando se há algum instrumental teórico que barre essa disposição para enfrentar a questão contemporânea.

\section{E oformalismo...}

Vou tomar um exemplo didático no sentido mais enfraquecido e mais banal, pois gosto sempre de comparar, relacionando em sala de aula com os estudantes, a maneira como Clement Greenberg analisa a lógica do plano, na pintura moderna, sobretudo nas leituras da pintura francesa desde Manet, passando por toda a arte europeia das décadas de 1910 a 1930.

A declaração enfática de uma arte de superfície é uma declaração da autonomia da arte, de um conhecimento que chega à maturidade na Idade Moderna e reclama seus fóruns sobre a emancipação de outras esferas do conhecimento postulando, portanto, essa reflexividade. É o mesmo diagnóstico que aparece no trabalho do Clark, sobretudo na abordagem da pintura parisiense do fim do século, onde há uma reintegração de uma lógica da superfície. Mas, na compreensão do Clark, é indissociável a lógica de superfície da própria topografia da cidade moderna, que é quadricular, sistêmica, onde as relações não são mais os afetos. São relações anônimas, impessoais. A própria lógica, do ponto de vista do urbanismo, da atividade construtiva, da arquitetura, da configuração da cidade, solicita uma lógica de superfície. É muito fina e sutil essa maneira de encontrar num trabalho de Monet, Manet ou Renoir a percepção da cidade moderna como um espaço fragmentado e de justaposição, onde as dimensões da ordem, do arbitrário e do acaso convivem e se complementam. Existe, portanto, a declaração ostensiva sobre esse espaço raso, queé dado e inconstante, que está aqui, masé permutado.É formidável a precisão do diagnóstico, que, aliás,éa mesma que você encontra no Greenberg, embora se trate de uma visão muito mais caudalosa e com capacidade de síntese e de apreensão da complexidade do fundamento cultural que me interessa. 


\section{Seria uma história da pintura?}

É absolutamente insatisfatória uma História da Arte que se reduzisse à história da pintura ou a uma história da visualidade porque a própria evidência da matéria cultural me sinaliza diferentemente. Toda a celebração do novo e do fragmento na obra do Charles Baudelaire, tanto na poesia como nos textos de crítica de arte dele, é indissociável da questão do urbanismo, da especulação imobiliária, da constituição dos grands magasins - a moda é feita pela primeira vez em escala industrial, não há mais a distinção de classe pelo modo de vestir; ela ocasiona uma padronização das camadas médias das populações urbanas. Portanto, essa lógica da justaposição do fragmento está em estruturas materiais precisas. Seria obtuso dizer que ela é um acontecimento específico na esfera da arte, embora na esfera da arte se dê problematicamente como uma espécie de enunciação densa de toda a questão cultural. Essa é a complexidade que as análises do Clark conseguem nos apresentar.

Há alguma análise de Clark que chame sua atenção por exemplificar essa abordagem?

Sobretudo, me agrada muito a análise da obra Olympia (1863), do Édouard Manet, porque demonstra a emergência de uma classe burguesa e a posição da mulher. Ao mesmo tempo, há uma sutileza do autor em perceber como naquele momento preciso e na relação de $\mathrm{Ma}$ net com a modelo, de alguma maneira, há quase que uma resistência daquele corpo a ser objetificado. Há uma insolência no olhar da moça que a gente sabe que é um cálculo do pintor - em qualquer posição de que se olhe para a obra, ela está sempre olhando para você de cima para baixo. Parece uma indicação de que talvez ela não esteja se expondo como uma mercadoria à venda, talvez ela tenha se assegurado de escolher o cliente. É um partido tomado pela análise do Clark nesse livro.

Ainda dentro da tradição marxista, há todo o trabalho do Theodor Adorno sobre indústria cultural. É um tipo de embocadura que me parece verdadeira, descontada do pessimismo e da desqualificação de tudo. Entretanto, o que não me parece satisfatório na maior parte das abordagens de esquerda que continuam a se produzir hojeé um ranço de determinismo. Há uma certa visão condescendente, uma mania de baratear a visão da arte. A arte é vista como algo sempre a posteriori, da ordem da representação, ou seja, o trabalho de arte é sempre tomado como documento de alguma outra coisa.

\section{Como você chegou a essa conclusão?}

Falo pensando nas minhas experiências mais recentes, do ponto de vista mais rigoroso de leitura acadêmica, realizadas principalmente durante a preparação do seminário internacional "Picasso: outros cri- 
térios" [realizado no Centro Universitário Maria Antonia - USP, em novembro de 2012].

Acabei consultando muitas bibliotecas virtuais, ficando meses na internet em arquivos digitais e procurando jovens autores para elaborar um mapeamento de quem estivesse escrevendo coisas novas e importantes sobre o Picasso. É curioso que dos anos 1980 para cá se produziram coisas importantes, se renovou a literatura sobre o modernismo, inclusive com a vinda à tona de documentação inédita sobre o construtivismo russo depois da queda do Muro de Berlim e da reconfiguração geopolítica mundial, com o acesso de pesquisadores do mundo inteiro aos arquivos da União Soviética. Sobre Picasso e Matisse, há muita coisa importante.

Durante essa pesquisa, tive contato com o trabalho tanto de autores que me pareceram suficientes, como de outros, insuficientes. Há, por exemplo, estudos importantes sobre as colagens mostrando que, nos trabalhos do Picasso do começo da década de 1910, os fragmentos de jornais e periódicos não são aleatórios. Há toda uma narrativa da situação - uma situação grave, que antecede a Primeira Guerra Mundial - na escolha desses papéis. Porém, a autora tem uma explicação muito mecanicista: não traça a biografia de um Picasso militante social e acaba fazendo um discurso eloquente das mensagens políticas, de uma carga ideológica da qual as colagens seriam portadoras. Evidentemente, é uma informação para um estudante de arte saber, mas providenciar uma explicação ideológica também é empobrecedor.

Poroutrolado, há os que se posicionam nalinhagem "greenberguiana". Um autor importante, que tem que ser lido pelos jovens que se interessam por arte, é o Michael Fried. Ele lançou há uns quatro anos um livro sobre fotografia que me parece uma abordagem absolutamente insatisfatória, tecendo uma mesma mística da autonomia, da pura visualidade em torno da fotografia, a mesma que se constituiu em torno da pintura nos moldes "greenberguianos". Fried tenta explicar a emergência da fotografia no trabalho de arte contemporânea como uma espécie de reivindicação de uma pureza da visão. Estou tomando, portanto, dois exemplos: o de uma crítica rebaixada, calcada em uma tradição marxista, e uma crítica calcada em uma linhagem "greenberguiana", que me parece insustentável.

Portanto, não é mais possível construir quadros muito seguros de abordagem da questão cultural.É preciso, modestamente, reconhecer a insuficiência ou as presunções de pureza ideológica desse campo disciplinar estabelecido, sem abrir mão dos avanços.

É impossível um estudante de arte não passar por um Greenberg, assim como ele não pode deixar de passar por um Michael Fried, embora não existam quadros teóricos seguros. A pretensão de construir teorias da arte sempre corre um risco de charlatanismo, de mistificação. Os textos do Arthur Danto são importantes, mas dizer que a arte 
finalmente morre porque ela se transforma em filosofia é um diagnóstico que não se sustenta. Não é que ela morra, mas se transforma em um império, um conceito, um pensamento, o artista agora elege qualquer objeto. Esse diagnóstico acaba sendo triste muito mais pela condição de prestígio que o marketing adquire, que a indústria do entretenimento adquire, do que propriamente algo que diga respeito a um novo estatuto teórico. Trata-se de uma pretensão generalizante. É preciso ter um pouco de humildade e lidar com as coisas mais no "caso a caso". Por conta disso, tenho dificuldade até para nomear o que faço.

\section{Você não se considera uma crítica de arte?}

Durante muito tempo, desde quando comecei, eu me declarava crítica de arte. Entretanto, faz alguns anos que, exceto por algumas situações muito esporádicas em que escrevi sobre um ou outro artista que me ocorreu - pois continuo acompanhando trabalhos de artistas que são importantes para a minha formação -, não tenho desenvolvido essa atividade. Não vejo mais a mesma importância que a crítica já teve no Brasil, especificamente, desde o começo do século, passando por Mário Pedrosa e Ferreira Gullar. Nos anos 80, seguramente, Ronaldo Brito e Rodrigo Naves. Essa situação se explica em face de uma fragilidade da tradição universitária na área de arte no Brasil, mas hoje em dia nós conseguimos ver com mais clareza queessa situação repercute, também, globalmente. Ela tem um certo lastro em fenômenos históricos locais, mas também surge de um campo de forças global. Dos anos 2000 para cá, me surpreende como aumentou o interesse pela arte. Há muita gente jovem querendo pensar arte, escrever sobre arte. O que mais me surpreendeé como essa nova produção sobre arte contemporânea praticamente varreu do mapa qualquer interesse por arte moderna. É como se houvesse uma dissociação lancinante entre o que se fazia cem anos atrás e o que se faz agora. Essa indiferença à experiência histórica me causa perplexidade. Por que não colocar em contraste fenômenos heterogêneos? Por que a arte holandesa do século XVII não deve interessar a um jovem artista? Falta um interesse pela perspectiva histórica, por um olhar verticalizado, pela experiência da análise comparativa não só no recorte da atualidade. Faltam análises sobre a arte brasileira e por contraste, sobretudo, com experiências cosmopolitas, como éo caso da Argentina, Venezuela, Uruguai.A literatura sobre arte contemporânea se ressente dessa indiferença.

Como você vê o percurso da crítica no Brasil desde 1960 - Aracy Amaral, Walter Zanini, Rodrigo Naves, Ronaldo Brito? Você não se inclui nesse percurso?

Não, pois estou muito distante. Não nos interesses, mas do ponto de vista de intervenção pública. Minha última grande pesquisa foi 
sobre a obra do Alfredo Volpi, publicada em livro pelo Centro Universitário Maria Antonia.

No começo dos anos 70, o meio de arte se profissionalizou, alguns arquivos se organizaram. Pesquisou-se a obra da Tarsila do Amaral. A universidade, bem ou mal, formou quadros, embora nem sempre seja o elemento a garantir uma boa formação. Essa jovem geração, por exemplo, busca se virar por conta própria. Trabalha com cultura, e esse contato bruto com o meio cultural me parece salutar.

Como disse, não sei se posso falar com muita autoridade, pois não estou acompanhando muito de perto o meio, muito voltada para o trabalho interno na universidade. Já tive uma atividade muito mais intensa de falar publicamente, dar conferência, fazer curadorias, e estou agora numa situação mais recolhida. Estou em contato com uma jovem geração, um trabalho de formação, um trabalho mais "interno", digamos. Portanto, talvez não tenha conhecimento específico sobre o que tem sido feito, mas, evidentemente, sou sensível ao meio e sei que muita coisa tem sido feita. Essa jovem geração tem recursos estimulantes, como sites sobre século XIX, a digitalização de bancos de informação de documentos etc. No entanto, é um enorme desafio que há pela frente porque, ao mesmo tempo em que houve essa profissionalização, que há quadros muito mais aptos e profissionalizados para trabalhar com arte, por outro lado, houve uma desagregação grande e importante de projetos culturais. É um desafio para vocês, pois muitos dos espaços culturais atuantes dos anos 1980 para cá não possuem acervo e frequentemente não têm projetos. E seguramenteé nesses lugares que vocês vão trabalhar!

Seria necessário providenciar uma conexão entre acervos e a experiência sensível do trabalho de arte, pois esses espaços correm o risco de se tornarem espaços geridos só por uma lógica de consumo, por uma relação de usuário e prestador de serviço. Sendo assim, é preocupante essa proliferação de espaços culturais e da ansiedade de militância que acompanhou o discurso sobre arte especialmente desde os anos 2000 , porque causou também a dissociação com a experiência sensível do trabalho. Houve uma ansiedade muito grande para uma ação e se perdeu a dimensão da elaboração. Essa ansiedade acabou elidindo a exigência dessa decantação. Um dos sintomas talvez seja essa dissociação que se encontra nos textos sobre a cultura contemporânea, nos quais as pessoas falam só das coisas que aconteceram no último ano. É uma cronologia muito rasa, superficial. Há um interesse posto, muita gente preparada, porque se criaram departamentos de artes visuais nas grandes universidades brasileiras, e é necessário um esforço para descompartimentar essa produção porque ela fica muito confinada. 
Precisaria haver uma repercussão do trabalho universitário de toda essa geração que se preparou no tipo de ação intensa que resultou na criação de inúmeros espaços culturais, que mobiliza a opinião pública, recursos públicos e privados. É preciso intervir nessa dissociação entre uma massa impressionante de eventos e a pouca possibilidade de intervenção de quadros preparados para tomar decisões. Portanto, há pouca decisão sendo tomada, pouca forma sendo burilada, pouca coisa sendo formalizada, para usar um termo importante na História da Arte.

\section{Esse diagnóstico diz respeito apenas ao meio artístico local?}

Não,égeral. Não tenho uma experiência tão grande, nunca vivi fora do Brasil, mas, pelo contato que tenho com o meio universitário, essa desqualificação do passado, de algo que tenha uma espessura histórica,é geral.Vocêencontra pouca gente, por exemplo, como o crítico Yves Alain-Bois, que é um crítico que fala com desenvoltura sobre Manet, Barnett Newman, e sobre uma artista contemporânea, como a Sophie Calle. É alguém que se põe nos diversos registros e que, embora tenha uma cultura importante sobre o modernismo e uma cultura histórica sofisticada, tem interesse pela situação contemporânea. Ageração dele circulou com muita desenvoltura, como a Rosalind Krauss, que consegue escrever admiravelmente bem sobre o Auguste Rodin e, ao mesmo tempo, Richard Serra. Trata-se de uma embocadura de visão. Não estou só falando de uma cronologia, estou falando de acolher objetos muito heterogêneos. O que me preocupa é o estreitamento do campo, se estamos sendo muito reativos às coisas, muito sintomáticos em vez de sermos propositivos. Essas fronteiras que se demarcaram entre o que é moderno e o que é contemporâneo - ao ponto de contemporâneo virar quase um adjetivo - isso não é algo que se possa escolher. Não há outro destino além de ser contemporâneo.

Como foi a discussão feita no seu mestrado, nos anos 1990, no qual você confronta a produção artística e as instituições legitimadoras no Brasil?

O mestrado foi uma experiência importante. Meu interesse pela arte surgiu de uma inquietação política. Eu era estudante nos anos 1970, um momento grave e soturno, muito deprimido culturalmente e, portanto, difícil para se ser jovem. Na verdade, deprimido-recalcado, porque tinha muita coisa vibrando por dentro. Esse trabalho, então, focaliza de uma maneira privilegiada a experiência do Centro Cultural São Paulo (CCSP) quando organizei um trabalho coletivo com uma equipe estimulante - com Fábio Miguez, Célia Euvaldo, Paulo Monteiro. O círculo foi se imantando, aumentando, trazendo camadas cada vez mais externas, heterogêneas, pois a ideia do Centro Culturalé 
sempre colocarem contato objetos muito díspares, "descaipirizar" um pouco aquela coisa paulista de ter núcleos muito endógenos. Portanto, naquele momento, trazer Leonilson, de um lado, e Nuno Ramos, de outro, eram expressões de campos bastante heterogêneos. Hoje em dia pode não parecer, mas, naquele momento, recolhia dimensões apartadas da realidade artística. E havia a pretensão de ser brasileira. Quando a coisa funcionou bem, a gente começou a convidar gente de fora de São Paulo.

Então, a dissertação de mestrado sistematiza o trabalho que pôde tomar um curso mais constante e se concretizar, amadurecer, porque havia essa solicitação do meio cultural pelo adensamento da ação cultural. Eu já tinha tido algumas passagens por órgãos públicos, sempre com uma vontade de pensar a arte a partir dessa solicitação de uma intervenção de maior curso em uma realidade cultural.

Assim, embora a dissertação seja ancorada na experiência do CCSP, ela fechava toda a expectativa política de uma geração que se torna adulta em meados dos anos 1970. O trabalho institucional no CCSP me enfeixava a outras experiências igualmente marcantes na minha vida: uma assessoria que fiz de alguns anos para a Funarte, viajando sempre para o Rio de Janeiro, opinando muito sobre editais, críticas e organizando muitos salões. Nos anos 1980, os salões tiveram um papel importante na reordenação da vida cultural brasileira. O Salão de Minas Gerais, em Belo Horizonte, era o mais importante culturalmente. Os salões de Brasília, São Paulo e Rio de Janeiro trouxeram à tona o trabalho de muita gente. Isso me deu experiência que, no CCSP, pôde tomar um outro fôlego articulando-se e encontrando uma ocasião política favorável - foi o primeiro governo do PT, que teve uma importância na renovação política. Também foi a primeira mulher a assumir a prefeitura de uma grande cidade brasileira. Era um momento de muita descoberta, um momento muito vigoroso culturalmentee bastante marcante para mim.

\section{E como era sua relação com a História da Arte?}

Eu sempre mevi muito mais como crítica de arte, e isso talvez tivesse algo de uma autoindulgência, pois eu achava que de um crítico seesperava beligerância, inquietação, inconformismo, mas não necessariamente uma formação intelectual rigorosa. O convívio mais profundo com a História da Arte veio muito depois, por causa do meu trabalho como professora no Departamento de Artes Plásticas da ECA-USP.A partir do final da década de 1990, comecei a estudar por conta própria História da Arte porque dava aulas sobre Florença no século XV. Então, estava dando aula sobre materiais que havia aprendido na noite anterior. Ainda faço isso, não deve ser tão chocante! Mas sempre tive essa visão do trabalho de crítica como uma intervenção muito presente que 
se dava pela oportunidade. A preocupação com a formação acadêmica mais consistente foi posterior, e espero que tenha agregado. Durante os quinze primeiros anos da minha atuação como crítica, fui muito movida pelo desejo de intervir aqui e agora. Por conta dessa busca de um domínio rigoroso, eu me vi forçada a ter uma biblioteca razoavelmente vasta sobre Renascimento, Barroco etc. É um luxo que a gente se dá aqui no Brasil, mas que pude me dar já tendo uma trajetória de alguns anos de atuação como crítica. O risco de falar de si mesmo e do seu passado é o risco de você edulcorar a origem. Mas, de todo modo, era preciso se pronunciar politicamente; não era uma escolha, era uma condição de vida. Não era possível ler o que se quisesse, então consultávamos pessoas mais velhas para emprestar livros. Éramos jovens, não tínhamos domínio de outras línguas, então líamos Adorno e Marx em espanhol. Havia toda uma tradição de esquerda que era proibida durante a ditadura militar e por isso era fundamental se posicionar. Faço parte de uma classe média que conseguiu colocar os filhos na universidade, um fato novo. Os primeiros filhos de classe média que saem de universidades são dos anos 1960 e 1970, são eles que se insubordinam contra os pais, contra o torpor repressivo de uma vida burguesa. Todos vivíamos uma realidade familiar sufocante e era preciso romper com o tipo de vida dos pais. Era preciso se livrar de alguma coerção porque havia sempre um cabresto sendo colocado em você, não só pela situação política geral, mas pelos costumes. A gente aprendia a se tornar um adulto independente dizendo não, brigando muito com seja lá quem for. Esse mau humor deve ter marcado uma geração.

\footnotetext{
Ainda há um descompasso entre a produção artística e as instituições culturais que você anuncia no seu mestrado?

Não, nunca houve tanta adesão! Nunca houve tanta política oficial, política pública para incentivar a produção de jovens artistas e curadores. Enfim, claro que é bom, não estou dizendo que a situação da privação era boa. Mas acaba trazendo outra ordem de poder. Não acho que você contribuir para a formação de um jovem artista seja apenas prover espaços de exposição. A exposição adquire uma importância social, cultural, absolutamente desproporcional, uma fetichização. A exposição deveria ser a culminação de um processo. Além disso, acontece muita coisa em termos de arte que não se resume à exposição: a instância do colecionador, a universitária, a instância do jovem pobre que não tem um ateliê e a da arte quando ela aparece na cidade, quando ela é instalada em locais públicos. Há um processo complexo que envolve interlocutores sociais e obstáculos sociais que a situação da exposição não consegue enunciar.

Então, me parece absolutamente tolo que haja quase que uma "filosofia das exposições". Abrem-se cursos universitários de curadoria.
} 
Não se trata apenas de ter bons curadores, o que é ótimo, mas é bom ter pessoas formadas intelectualmente, rigorosamente formadas, que possam atuar como curadores e eventualmente também na retaguarda de um espaço cultural, não necessariamente fazendo exposição. É curioso e sintomático que a exposição tenha se tornado um objeto. Atualmente, a gente lembra muito mais o nome da exposição e o trabalho de arte que foi mostrado do que o artista.

Ao compreender a situação cultural como se ela pudesse ser enunciada em uma agenda de exposições, perde-se a dimensão do processo que envolve a produção de conhecimento e que emboca a produção cultural propriamente. Por que se pensa queé importante formar curadores, mas não arquivistas, educadores, montadores de exposição, gente com experiência naquilo que se chama de expografia? Ou seja, há uma complexidade na maneira como o conhecimento se produz na situação contemporânea e é preciso sensibilizar as pessoas jovens para essas áreas. A exposição é um dos objetos; entretanto, o campo editorial é também um campo que exponencialmente se amplia com o mundo digital. Precisamos formar gente para ocupar e intervir em todos esses espaços. É quase uma mistificação descrever as grandes preocupações só como se fosse a curadoria, na verdade, é nesse momento que se leva uma proposição ao público em uma situação institucional.

Como você vê os métodos, abordagens ou pontos de vista atuais da História da Arte praticada no país?

É umlugar onde tudo está por fazer, tudo pede para ser reordenado, reconfigurado. Deveríamos encarar com mais sobriedade e realismo essa modéstia de não pretender mais essas grandes generalizações, os pontos de vista totalizantes. Isso é uma particularidade brasileira, pois gostamos muito do Giulio Carlo Argan. Todos os departamentos de artes visuais recomendam o Argan, que é um autor com um resquício e uma nostalgia da arte moderna. Por muitos anos, eu repetia para os alunos, logo que começava a dar aula: "Dois artistas referenciais para a arte do século XIX: de um lado, Vincent Van Gogh e, de outro, Paul Cézanne". Nesse grande compêndio que é o Arte moderna: do Iluminismo aos movimentos contemporâneos [São Paulo: Companhia das Letras, 1992 ], há uma formulação do Argan de que a arte moderna é uma culminação de duas fontes antagônicas postas por esses dois artistas. De um lado, esse clamor de inconformismo informe que é o Van Gogh e, do outro, as correntes construtivas, que seria o Cézanne. Com o tempo, fui percebendo como era limitadora, sobretudo nas aulas sobre o próprio Cézanne, a descrição desse trabalho como movido somente por um ânimo construtivo. Há muito vazio, há muito interstício na pintura do Cézanne, e por isso é importante perceber as dimensões 
de desconstrução do trabalho. O Argan, ainda que seja um historiador muito fino, que fornece tantas pistas importantes para pensarmos o presente, tem algo dessa nostalgia do moderno que nos confina, nos delimita, impede que a gente tenha uma visão mais livre do presente. Dessa convivência de construção e desconstrução no Cézanne, e talvez no Van Gogh, há uma matéria que é amassada. É um esforço titânico para não deixaro mundo escorrer,então posso dizerque há construção também no Van Gogh.

Nós começamos a nossa conversa falando da insuficiência do campo disciplinar,e talvez pareça contraditório reclamaruma embocadura de visão, ou seja, reclamar que a gente não se interesse pelas coisas que foram feitas nos últimos doze meses, ao mesmo tempo em que é uma condição de trabalho essa embocadura. Mas solicito esse abrir mão da possibilidade dos grandes diagnósticos e das grandes categorias. Espero que não sejam entendidos como contraditórios estes pleitos: abrir mão dessa pomposidade e da visão monumental para se debruçar mais modestamente sobre os objetos incompletos, mais rente sobre eles.

A Ana Avelar havia usado a palavra "metodologia" antes de iniciarmos a gravação, mas não sei se essa palavra é boa porque "metodologia" parece que é um instrumento neutro ao qual você recorre, e não há essa distinção entre o queé meio e o que é fim no trabalho de compreensão. Para mim, são muito mesclados os processos aos quais recorremos para compreender. É o próprio objeto que sinaliza e que não pode ser abstraído. Eu meesquivaria de responder sobre metodologia, embora todos os pedidos de verbas para agências federais perguntem sobre metodologia. É um ranço positivista de cultura universitária: você finge que está respondendo sobre metodologia. Não há uma instância de metodologia à qual se recorre como se fosse um elenco de procedimentos que seja líquido e certo.

Você identifica na História da Arte no Brasil uma "grande narrativa" nos moldes modernos?

Nós não temos uma grande narrativa, e não sei se isso é uma insuficiência, pois não sei se é bom ter uma grande narrativa. Talvez o problema brasileiro seja que ainda não produzimos uma narrativa forte, convincente, que seja multifacetada. Não estou dizendo que deva haver uma modelar, que sirva de padrão, mas talvez nos falte ainda essa tarefa de percebermos uma articulação cultural. Todas as pesquisas que foram feitas sobre os movimentos construtivos dos anos 1950, não só no campo das artes visuais, mas também na arquitetura, no cinema e até na música popular, produziram uma sistematização de bibliografia sobre esse período. Isso demonstra que esse período é um capítulo importante no século XX para qualquer História da Arte que 
se escreva, não só para a arte brasileira. Você não pode passar sobre a modernidade sem falar como, por exemplo, a bossa nova se apropria das raízes do samba, da música popular, do jazz, e se irradia.Ao mesmo tempo em que tem um calor e uma espessura local forte, ela consegue se universalizar. A respeito desse período já há muito material importante consolidado. Entretanto, o empenho de vocês, que estão com essa responsabilidade que está se apresentando hoje, talvez seja justamente desconstruir essa ideia de grande narrativa. Talvez "construir uma grande narrativa" tenha se tornado uma banalidade. Não é o caso de supor que se ponha agora a tarefa de escrever histórias nacionais, histórias da modernidade nacional em cada país porque isso é uma tolice, embora existam, seguramente, modernismos. Esse foi um dos motivos pelos quais propus ao T.J. Clark dar esse título ao livro dele [Modernismos: ensaios sobre política, história e teoria da arte. São Paulo: Cosac Naify, 2007], pensando em uma visão multifacetada, mais complexa do que terá sido a experiência da modernidade no século XX fora dos grandes centros. Esse é um horizonte de ação importante para a arte brasileira: compreender melhor as articulações no século XX, os momentos em que ela culmina, em que ela formaliza, ganha essa consistência, se apresenta como um capítulo no cenário internacional da pintura. É necessário esse trabalho de sistematização.

\section{Essa perspectiva nacionalista aparece em que momentos da História} daArte no Brasil?

Há um clima de revisionismo militante a partir dos anos 1980, como se as histórias nacionais pudessem ser uma resposta. Existem momentos importantes da nossa História da Arte, mas eles não se explicam à luz de uma lógica nacionalista, embora componentes de um nacionalismo, sobretudo no caso brasileiro, sejam certamente relevantes. Você não vai encontrar um modernismo uruguaio, um modernismo colombiano, um modernismo equivalente a cada nação latino-americana.

Mesmo para a arte brasileira, há um momento culminante nos anos 1950 e 1960, mas não sei se esse momento culminante se repetirá ao longo do século XX - me parece que não. Não quer dizer que tenha havido um declínio, pode querer dizer que tenhamos ingressado num certo ritmo de normalidade, estamos tão em sintonia com o cenário internacional que não surpreendemos mais com uma manifestação porque conquistamos uma qualidade média. Em um dos eventos que organizo com o grupo de estudantes de graduação e pós-graduação no Departamento de Artes Plásticas desde 2005 , convidamos a crítica de arte indiana Guita Kapuri, acho que em 2007 ou 2008 , para dar uma palestra sobre o modernismo na Índia na década de 1920 . 
Recebido para publicação em 30 de abril de 2015 .

\section{NOVOS ESTUDOS}

CEBRAP

101, março 2015

pp. 141-155
São assuntos que a gente desconhece e que é importante a gente saber porque provavelmente é alguma experiência que possui uma conexão com a dimensão cosmopolita da experiência moderna, dos grandes centros, mas que, ao mesmo tempo, tensiona algo da experiência cultural indiana. Conhecer o presente pressupõe também essa visão mais livre. Se fez muito proselitismo, muita militância, mas não se colocou nada no lugar. Desconstruir as grandes narrativas não basta porque isso pode ser um rancor, um ressentimento. Então, que a gente se lance agora à tarefa construtiva de compreender o que se constitui, porque de outra maneira fica muito compensatório! Ao desconstruir as grandes narrativas, você acaba construindo uma narrativa que é reativa à grande narrativa. Minha expectativa é que a gente saia dessa lógica maniqueísta.

\section{Para finalizar, quem você considera seus interlocutores?}

No livro Art since 1900 (Londres: Thames and Hudson, 2004), os autores, herdeiros de uma tradição marxista, que se lançaram à análise e à crítica da situação contemporânea, expõem de onde falam - Rosalind Krauss, Hal Foster, Benjamin H.D. Buchloh etc. Yve-Alain Bois, evidentemente, vem do estruturalismo; um outro, da psicanálise; a Rosalind Krauss, também do estruturalismo. Hal Foster dialoga um pouco com a tradição marxista, combinada à psicanálise e à Escola de Frankfurt.

Eu não conseguiria delimitar fronteiras muito nítidas nem dosar minhas referências teóricas. Para um pensamento crítico, não há como não partir da Escola de Frankfurt. Até para avançar, para sair da ranzinzice, daquela operação negativa, daquela depressão.

Ao contrário desses teóricos, não saberia escrever uma introdução para falar de onde parto, o que não me tranquiliza, mas entendo que essa ambiguidadée constitutiva do momento presente. Emvez de tentar fazer prospecções e previsões, o que seria mistificador, o momento recomenda sobriedade, modéstia. Mas vamos lá, vamos continuar brigando, embora agora a briga maior seja comigo mesma.

ANA CÂNDIDA DE Avelar é professora adjunta de Teoria, Crítica e História da Arte do Departamento de Artes Visuais da UnB. Coordena o Núcleo de Pesquisa e Mediação do Centro Universitário Maria Antonia, da USP, é crítica de arte e curadora. 